\title{
Faktor Penyebab Kematian Ibu di Provinsi Aceh Tahun 2015-2016
}

\author{
Factors Causing The Death of Mother Aceh Province in 2015-2016 \\ Faradilla Safitri*1 $^{1}$, Marniati ${ }^{2}$ \\ ${ }^{1}$ Prodi D-IV Kebidanan, Fakultas Ilmu Kesehatan, Universitas Ubudiyah Indonesia, Jalan Alue Naga Desa Tibang, \\ Kecamatan Syiah Kuala, Banda Aceh, Indonesia \\ ${ }^{2}$ Prodi Ilmu Kesehatan Masyarakat, Fakultas Ilmu Kesehatan, Universitas Ubudiyah Indonesia, Jalan Alue Naga Desa \\ Tibang, Kecamatan Syiah Kuala, Banda Aceh, Indonesia \\ *Korespondensi Penulis: faradilla@uui.ac.id
}

\begin{abstract}
Abstrak
Angka Kematian Ibu masih menjadi masalah terbesar diseluruh Indonesia, salah satunya di Provinsi Aceh, walaupun angka kematian ini setiap tahunnya sudah mulai menurun. Tujuan penelitian ini adalah untuk mengetahui faktor penyebab kematian ibu yang ada di provinsi aceh. Jenis penelitian bersifat deskriptif yang berarti hanya melihat gambaran umum faktorfaktor yang dapat menyebabkan kematian pada ibu. Hasil penelitian didapatkan hasil bahwa pada tahun 2015 penyebab utama kematian ibu di provinsi aceh adalah karena perdarahan yaitu sebesar 39 kasus (29.1\%), pre eklampsi/eklampsi sebesar 27 kasus (20.2\%) dan komplikasi lainnya sebesar 27 kasus (20.2\%). Dan pada tahun 2016, penyebab terbesar kematian ibu di provinsi aceh masih didominasi oleh perdarahan yaitu 55 kasus $(32.5 \%)$, disusul oleh pre eklampsi/eklampsi sebanyak 36 kasus $(21.3 \%)$ dan penyebab lain yang tidak berhubungan secara langsung dengan kematian ibu yaitu sebesar 32 kasus (18.9\%). Berdasarkan hasil penelitian dapat disimpulkan bahwa Penyebab secara langsung yang paling besar angka kematian ibu ini disebabkan oleh kejadian perdarahan. Perdarahan yang dimaksud adalah perdarahan primer dan perdarahan sekunder. Selanjutnya disusul dengan kejadian pre eklampsia dan eklampsia dan beberapa penyebab lain selama kehamilan, persalinan dan nifas.
\end{abstract}

Kata kunci : AKI, Aceh

\begin{abstract}
The Maternal Mortality Rate is still the biggest problem in all of Indonesia, one of them is in Aceh Province, although this mortality rate has begun to decline every year. The purpose of this study was to determine the factors that cause maternal mortality in Aceh Province. This type of research is descriptive which means it only sees a general description of the factors that can cause death in the mother. The analysis used is univariate analysis. The results showed that in 2015 the main cause of maternal mortality in Aceh Province was due to bleeding, which amounted to 39 cases (29.1\%), preeclampsia / eclampsia of 27 cases (20.2\%) and other complications of 27 cases (20.2\%). And in 2016, the biggest cause of maternal mortality in Aceh province was still dominated by bleeding, namely 55 cases (32.5\%), followed by pre-eclampsia / eclampsia in 36 cases (21.3\%) and other causes that were not directly related to maternal mortality which was equal to 32 cases (18.9\%). Based on the results of the study it can be concluded that the direct cause of the greatest maternal mortality rate is caused by the incidence of bleeding. Bleeding in question is primary bleeding and
\end{abstract}


secondary bleeding. Then followed by the occurrence of pre-eclampsia and eclampsia and several other causes during pregnancy, childbirth and childbirth.

Keywords : Maternal Mortality Rate, Aceh

\section{PENDAHULUAN}

Pembangunan kesehatan bertujuan meningkatkan kesadaran, kemauan dan kemampuan hidup sehat bagi setiap orang agar dapat mewujudkan derajat kesehatan yang optimal. Derajat kesehatan merupakan salah satu faktor yang sangat berpengaruh terhadap kualitas sumberdaya manusia, karena hanya dengan sumberdaya manusia yang sehat akan lebih produktif dan meningkatkan daya saing manusia serta daya saing suatu daerah. Derajat kesehatan manusia dipengaruhi oleh beberapa faktor yaitu keadaan lingkungan, perilaku, pelayanan kesehatan dan keturunan (Dinkes Aceh, 2016).

Keberhasilan upaya kesehatan ibu, diantaranya dapat dilihat dari indicator Angka Kematian Ibu (AKI). AKI adalah jumlah kematian ibu selama masa kehamilan, persalinan dan nifas yang disebabkan oleh kehamilan, persalinan dan nifas atau pengelolaannya tetapi bukan karena sebab-sebab lain seperti kecelakaan atau terjatuh di setiap 100.000 kelahiran hidup (Kemenkes RI, 2016).

AKI juga dapat digunakan dalam pemantauan kematian terkait dengan kehamilan. Indikator ini dipengaruhi oleh status kesehatan secara umum, pendidikan dan pelayanan selama kehamilan dan melahirkan. Sensitifitas AKI terhadap perbaikan pelayanan kesehatan menjadikannya indikator keberhasilan pembangunan sektor kesehatan (Dinkes Aceh, 2016).

Angka kematian ibu sangat tinggi. Sekitar 830 wanita meninggal karena komplikasi kehamilan atau persalinan di seluruh dunia setiap hari. Rasio kematian maternal global (jumlah kematian ibu per 100.000 kelahiran hidup) menurun hanya 2,3\% per tahun antara 1990 dan 2015. Namun, peningkatan tingkat penurunan mortalitas ibu hamil meningkat dari tahun 2000 dan seterusnya. Di beberapa negara, penurunan angka kematian ibu hamil antara 2000-2010 di atas 5,5\%. (WHO, 2016).

Aceh merupakan salah satu provinsi yang ada di Indonesia dan terletak dibagian paling barat gugusan kepulauan Nusantara. Angka Kematian Ibu menjadi salah satu indicator penting dalam menentukan derajat kesehatan masyarakat khususnya Aceh. Pada Tahun 2015 Angka Kematian Ibu di Aceh didominasi oleh kematian ibu nifas yaitu sebanyak 70 ibu (52\%), ibu bersalin sebanyak 34 ibu (25\%) dan kematian ibu dalam keadaan hamil sebanyak 
$30 \mathrm{ibu}$ (23\%). Terjadi penurunan AKI Tahun 2016 yang proporsi kematian ibu masih di dominasi oleh kematian ibu nifas 76 kasus (45\%), diikuti kematian ibu bersalin sebanyak 65 kasus (38\%) dan kematian ibu dalam keadaan hamil sebanyak 28 kasus (17\%).

Angka Kematian Ibu di tujuh tahun terakhir juga berfluktuasi. Dari data yang bersumber pada dinas kesehatan kabupaten/kota, diketahui jumlah kematian ibu di Aceh yang dilaporkan adalah 169 kasus dan lahir hidup 101.249 jiwa, maka rasio angka kematian ibu di Aceh tahun 2016 sebesar 167 per 100.000 kelahiran hidup,meningkat dari tahun sebelumnya yaitu 134per 100.000 kelahiran hidup, hal ini menjadi tantangan bagi Pemerintah Aceh untuk lebih meningkatkan komitmen daerah dalam memberikan pelayanan kesehatan ibu hamil, ibu bersalin dan ibu nifas. Daerah terbanyak memberi kontribusi pada kematian ibu di Aceh adalah Kabupaten Aceh Utara dengan jumlah kematian ibu mencapai 26 kasus, diikuti Aceh Timur sebanyak 21 kasus dan Bireuen 11 kasus serta kabupaten/kota lainnya di Aceh yang capaiannya antara 1 sampai 9 kasus.

Wanita meninggal akibat komplikasi selama dan setelah kehamilan dan persalinan. Sebagian besar komplikasi ini berkembang selama kehamilan dan sebagian besar dapat dicegah atau diobati. Komplikasi lain mungkin ada sebelum kehamilan namun memburuk selama kehamilan, terutama jika tidak ditangani sebagai bagian dari perawatan wanita. Komplikasi utama yang menyebabkan hampir $75 \%$ kematian maternal ada 4 hal yaitu pendarahan hebat (sebagian besar berdarah setelah melahirkan), infeksi (biasanya setelah persalinan), tekanan darah tinggi selama kehamilan (preeklampsia dan eklampsia), komplikasi dari persalinan aborsi tidak aman. Selain itu ada pula yang disebabkan oleh atau terkait dengan penyakit seperti malaria, dan AIDS selama kehamilan dan lain-lain. Sebagian besar kematian ibu dapat dicegah, karena solusi perawatan kesehatan untuk mencegah atau menangani komplikasi sudah diketahui. Semua wanita membutuhkan akses terhadap perawatan antenatal pada kehamilan, perawatan yang terampil selama persalinan, dan perawatan serta dukungan pada minggu-minggu setelah melahirkan (WHO, 2016).

\section{METODE PENELITIAN}

Penelitian ini bersifat deskriptif yang bertujuan untuk mengetahui faktor penyebab kematian ibu di Provinsi Aceh tahun 2015-2016. Pengumpulan data telah dilaksanakan pada tanggal 5 Maret 2018 di Dinas Kesehatan Aceh. Populasi dalam penelitian ini adalah seluruh 
ibu yang meninggal (pada masa kehamilan, persalinan dan nifas) yaitu sebanyak 304 kasus. Pengumpulan data pada penelitian ini menggunakan data sekunder yaitu data dari bidang kesehatan masyarakat yang mendata jumlah kematian ibu serta data dari buku profil Dinas Kesehatan Aceh. Analisis data menggunakan analisis univariat.

\section{HASIL DAN PEMBAHASAN}

Tabel 1. Distribusi Frekuensi Angka Kematian Ibu di Provinsi Aceh Tahun 2015

\begin{tabular}{clcc}
\hline No & Masa & Frekuensi (f) & Persentase (\%) \\
\hline 1 & Ibu Hamil & 30 & 23.0 \\
2 & Ibu Bersalin & 34 & 25.0 \\
3 & Ibu Nifas & 70 & 52.0 \\
\hline \multicolumn{2}{c}{ Total } & $\mathbf{1 3 4}$ & $\mathbf{1 0 0 . 0}$ \\
\hline
\end{tabular}

Berdasarkan Tabel 1 diatas dapat dilihat bahwa angka kematian ibu di dominasi oleh kematian ibu nifas yaitu sebanyak 70 orang (52\%), kematian ibu bersalin sebanyak 34 orang (25\%), dan kematian ibu hamil sebanyak 30 orang (23\%).

Tabel 2. Distribusi Frekuensi Angka Kematian Ibu di Provinsi Aceh Tahun 2016

\begin{tabular}{clcc}
\hline No & Masa & Frekuensi (f) & Persentase (\%) \\
\hline 1 & Ibu Hamil & 28 & 17 \\
2 & Ibu Bersalin & 65 & 38 \\
3 & Ibu Nifas & 76 & 45 \\
\hline Total & $\mathbf{1 6 9}$ & $\mathbf{1 0 0}$ \\
\hline
\end{tabular}

Berdasarkan Tabel 2. diatas dapat dilihat bahwa angka kematian ibu masih di dominasi oleh kematian ibu nifas yaitu sebanyak 76 orang (45\%), kematian ibu bersalin sebanyak 65 orang (38\%), dan kematian ibu hamil sebanyak 28 orang (17\%).

Tabel 3. Distribusi Frekuensi Penyebab Angka Kematian Ibu di Provinsi Aceh Tahun 2015

\begin{tabular}{clcc}
\hline No & \multicolumn{1}{c}{ Faktor Penyebab } & Frekuensi (f) & Persentase (\%) \\
\hline 1 & Perdarahan & 39 & 29.1 \\
2 & Pre Eklampsi/ Eklampsi & 27 & 20.2 \\
3 & Sepsis Puerperium & 12 & 9.0 \\
4 & Emboli Air Ketuban & 1 & 0.7 \\
5 & Kehamilan Ektopik & 1 & 0.7 \\
\hline
\end{tabular}




\begin{tabular}{clcc}
\hline 6 & Hipertensi & 8 & 6.0 \\
7 & Anemia & 1 & 0.7 \\
8 & Syok Hipovolemik & 3 & 2.2 \\
9 & Abortus & 2 & 1.5 \\
10 & Inversio Uteri Post SC & 2 & 1.5 \\
11 & Hiperemesis Gravidarum & 2 & 1.5 \\
12 & Lain-lain & 27 & 20.2 \\
13 & Tidak Diketahui & 9 & 6.7 \\
\hline \multicolumn{2}{r}{ Total } & $\mathbf{1 3 4}$ & $\mathbf{1 0 0}$ \\
\hline
\end{tabular}

Berdasarkan Tabel 3. dapat dilihat bahwa penyebab utama kematian ibu di provinsi aceh adalah karena perdarahan yaitu sebesar 39 kasus (29.1\%), pre eklampsi/eklampsi sebesar 27 kasus (20.2\%) dan komplikasi lainnya sebesar 27 kasus (20.2\%).

Tabel 4. Distribusi Frekuensi Penyebab Angka Kematian Ibu di Provinsi Aceh Tahun 2016

\begin{tabular}{clcc}
\hline No & \multicolumn{1}{c}{ Penyebab } & Frekuensi (f) & Persentase (\%) \\
\hline 1 & Perdarahan & 55 & 32.5 \\
2 & Pre Eklampsi/ Eklampsi & 36 & 21.3 \\
3 & Infeksi Post SC & 10 & 5.9 \\
4 & Post SC & 6 & 3.6 \\
5 & Emboli Air Ketuban & 2 & 1.2 \\
6 & Kehamilan Ektopik & 2 & 1.2 \\
7 & Hipertensi & 2 & 1.2 \\
8 & Anemia & 2 & 1.2 \\
9 & Nyeri Epigastrium dan Simpisis & 2 & 1.2 \\
10 & Abortus & 1 & 0.6 \\
11 & Inversio Uteri & 1 & 0.6 \\
12 & Hiperemesis Gravidarum & 2 & 1.2 \\
13 & Komplikasi masa nifas & 1 & 0.6 \\
14 & Sesak & 8 & 4.7 \\
15 & Hepatitis & 1 & 0.6 \\
16 & Meningitis & 1 & 0.6 \\
17 & Infeksi Saluran Kemih & 1 & 0.6 \\
18 & Lain-lain & 32 & 18.9 \\
19 & Tidak Diketahui & 4 & 2.4 \\
\hline & $\quad$ Total & $\mathbf{1 6 9}$ & $\mathbf{1 0 0}$ \\
\hline
\end{tabular}

Berdasarkan Tabel 4. dapat dilihat bahwa penyebab terbesar kematian ibu di provinsi aceh masih didominasi oleh perdarahan yaitu 55 kasus (32.5\%), disusul oleh pre 
eklampsi/eklampsi sebanyak 36 kasus (21.3\%) dan penyebab lain yang tidak berhubungan secara langsung dengan kematian ibu yaitu sebesar 32 kasus (18.9\%).

Angka Kematian Ibu (AKI) termasuk salah satu indicator penting dalam menentukan derajat kesehatan masyarakat. AKI menggambarkan jumlah ibu yang meninggal dari suatu penyebab kematian terkait dengan gangguan kehamilan atau penanganannya (Tidak termasuk kecelakaan atau kasus insidentil) selama kehamilan, melahirkan dan dalam masa nifas (42 hari setelah melahirkan) tanpa memperhitungkan lama kehamilan per 100.000 kelahiran hidup.

Hasil penelitian ini sejalan dengan penelitian yang telah dilakukan oleh Aeni di Kabupaten Pati tahun 2011 didapatkan hasil bahwa faktor yang berpengaruh terhadap kematian ibu adalah komplikasi kehamilan ( $\mathrm{OR}=12,198$, nilai $\mathrm{p}=0,010)$, komplikasi persalinan $(\mathrm{OR}=9,94$, nilai $\mathrm{p}=0,020)$ dan riwayat penyakit $(\mathrm{OR}=27,735$, nilai $\mathrm{p}=0,011)$.

Hasil penelitian ini sejalan dengan teori yang disampaikan Wiknjosastro (2008), perdarahan obstetric yang terjadi pada kehamilan trimester ketiga dan yang terjadi setelah anak plasenta lahir pada umumnya adalah perdarahan yang berat, dan jika tidak segera mendapatkan penanganan yang cepat bisa mendatangkan syok yang fatal.

Selain perdarahan selama kehamilan, yang menjadi masalah besar juga adalah perdarahan postpartum yang disebabkan antara lain oleh atonia uteri, retensio plasenta, laserasi jalan lahir, dan kelainan penyakit darah. Adapun faktor-faktor predisposisi perdarahan postpartum menurut Varney (2008) antara lain paritas, umur kehamilam, jarak persalinan, peregangan uterus berlebih (makrosomia, gemeli dan polihidramnion), partus presipitatus, induksi oksitosin, riwayat seksio sesaria, riwayat perdarahan postpartum dan kala I dan II yang memanjang. Sedangkan menurut Winkjosastro (2007) faktor obstetric perdarahan postpartum antara lain riwayat perdarahan postpartum, partus lama, anemia dan penanganan yang salah pada kala III.

Pre-eklampsia dan eklampsia adalah penyakit hipertensi yang terjadi pada kehamilan yang ditandai dengan hipertensi, edema, dan proteinuria setelah minggu ke-20, dan jika disertai kejang disebut eklampsia (Nuryani, 2012).

Penyebab kematian ibu selanjutnya adalah infeksi masa nifas. Infeksi ini bisa menyerang alat genital yang sehingga dapat menyebabkan komplikasi masa nifas. Menurut 
Bahiyatun (2009), infeksi yang meluas ke saluran urinari, payudara, dan pasca pembedahan merupakan penyebab terjadinya AKI tinggi. Gejala umum infeksi dapat dilihat dari suhu, pembengkakan, takikardia dan malaise. Gejala lokalnya berupa uterus lembek, kemerahan, rasa nyeri pada payudara, atau adanya disuria Infeksi juga merupakan penyebab penting kematian dan kesakitan ibu. Menurut Saifuddin (2009), insidensi infeksi nifas sangat berhubungan dengan praktik tidak bersih pada waktu persalinan dan nifas.

Penyumbang angka kematian selanjutnya adalah masalah kesehatan yang tidak berhubungan secara langsung dengan kematian ibu yaitu seperti penyakit jantung, asma dan beberapa penyakit lainnya. Hal ini sesuai dengan teori yang disampaikan oleh Prawirohardjo (2008), yang mengatakan bahwa kematian ibu dibagi kedalam 2 bagian, yaitu kematian obstetri langsung dan kematian obstetri tidak langsung. Kematian obstetri tidak langsung yaitu kematian yang timbul akibat adanya penyakit penyerta yang sudah diderita sebelum kehamilan dan persalinan atau penyakit yang timbul pada saat kehamilan yang tidak berkaitan dengan penyebab obstetri langsung, tetapi dapat diperburuk oleh pengaruh fisiologik akibat kehamilan seperti penyakit jantung, anemia, malaria, dan HIV / AIDS.

Hasil penelitian juga ditemui beberapa kasus kematian ibu tidak diketahui penyebabnya secara pasti, seperti pada tahun 2015 sebanyak 9 orang (6.7) ibu meninggal dan tahun 2016 sebanyak 4 orang $(2.4 \%)$, namun ada juga penyebab kematian ibu yang tidak tertera penjelasan secara spesifiknya seperti kematian ibu post SC sebanyak 6 orang (3.6\%).

Selama melakukan pengumpulan data, peneliti sangat mengalami kesulitan dalam mengkategorikan penyebab kematian ibu secara lebih spesifik. Hal ini dikarenakan banyak dijumpai data-data yang tidak tertulis secara jelas penyebab kematian ibu, seperti pada diagnosis perdarahan, tidak dijelaskan perdarahan pada masa kapan dan apa yang menyebabkan perdarahan itu bisa terjadi dan lain sebagainya.

Berdasarkan hasil penelitian dan beberapa teori yang telah dibahas diatas, peneliti berasumsi bahwa penyebab kematian ibu di Provinsi Aceh pada tahun 2015 dan 2016 adalah perdarahan, pre eklampsi/eklampsi, infeksi masa nifas dan masalah kesehatan lainnya. Perdarahan dapat terjadi tanpa diduga dan menjadi momok yang paling menakutkan bagi para ibu dan petugas kesehatan. Untuk mencegah terjadinya perdarahan hingga menyebabkan kematian, maka petugas kesehatan dapat memberikan pemahaman kepada ibu selama kehamilan harus melakukan pemeriksaan secara rutin minimal $4 \mathrm{x}$, dengan tujuan agar dapat 
mengontrol kondisi ibu dan janin, serta dapat mendeteksi komplikasi yang mungkin akan terjadi pada ibu hamil. Apabila perdarahan telah terjadi baik dimasa kehamilan, bersalin dan nifas, maka petugas kesehatan dapat menangani dengan cepat dan tepat agar dapat menyelamatkan nyawa ibu dan tetap melakukan tindakan sesuai dengan teknik pencegahan infeksi, agar ibu terhindar dari infeksi pada masa nifas.

Pre eklampsi/eklampsi menjadi penyebab kedua kematian ibu. Pre eklampsi ini sebenarnya dapat dideteksi secara dini dan dapat dilakukan pertolongan awal agar tidak sampai menjadi eklampsi. Konseling dan penanganan yang tidak tepat pada ibu yang terdiagnosis mengalami pre eklampsi maka berdampak mematikan untuk ibu dan janinnya.

Infeksi masa nifas menjadi penyebab ketiga kematian ibu. Hasil penelitian didapatkan bahwa infeksi terbanyak disebabkan oleh persalinan sesara sesar. Hal ini dapat disebabkan oleh pencegahan infeksi yang tidak baik, serta kemungkinan penyakit infeksi yang sebelumnya diderita ibu. Tanda awal ibu mengalami infeksi adalah mengalami demam. Infeksi pada masa nifas dapat dicegah, pencegahan dan penanganan yang tidak tepat berdampak kematian bagi ibu. Infeksi nifas ini menjadi hal yang sangat fatal jika terjadi, karena ini menjadi kelalaian dari para petugas kesehatan.

\section{KESIMPULAN}

Berdasarkan penelitian yang telah dilakukan maka dapat disimpulkan bahwa angka kematian ibu pada tahun 2015 di dominasi oleh kematian ibu nifas yaitu sebanyak 70 orang (52\%), kematian ibu bersalin sebanyak 34 orang (25\%), dan kematian ibu hamil sebanyak 30 orang (23\%). Penyebab secara langsung yang paling besar angka kematian ibu ini disebabkan oleh kejadian perdarahan. Perdarahan yang dimaksud adalah perdarahan primer (perdarahan yang terjadi selama 24 jam setelah melahirkan) dan perdarahan sekunder (perdarahan yang terjadi setelah 24 jam persalinan). Selanjutnya disusul dengan kejadian pre eklampsia dan eklampsia dan beberapa penyebab lain selama kehamilan, persalinan dan nifas.

Angka kematian ibu pada tahun 2016 masih juga di dominasi oleh kematian ibu nifas yaitu sebanyak 76 orang (45\%), kematian ibu bersalin sebanyak 65 orang (38\%), dan kematian ibu hamil sebanyak 28 orang (17\%). Penyebab langsung kematian ibu ini juga masih didominasi oleh kejadian perdarahan dan pre eklampsi/eklampsi dan beberapa penyebab lainnya. 


\section{SARAN}

Diharapkan kepada petugas kesehatan agar dapat lebih meningkatkan lagi mutu pelayanan kesehatan. Bentuk-bentuk program yang dapat dilakukan secara berkesinambungan seperti penyuluhan kesehatan, pembagian brosur, pemasangan spanduk dan baliho tentang faktor penyebab kematian ibu, serta yang paling utama, petugas kesehatan memberikan pelayanan kesehatan yang prima, cepat dan tepat tanggap dalam menghadapi masalah kesehatan dengan harapan agar dapat menurunkan angka kematian ibu pada ibu khususnya di Provinsi Aceh.

\section{UCAPAN TERIMA KASIH}

Ucapan terima kasih kepada Universitas Ubudiyah Indonesia yang telah memberikan dukungan finansial dalam penelitian ini dan ucapan terima kasih kepada Kepala Dinas Kesehatan Provinsi Aceh yang telah memberikan izin penelitian.

\section{DAFTAR PUSTAKA}

Aeni, Nurul. (2011). Faktor Risiko Kematian Ibu. Artikel Ilmiah, Vol. 7 No. 10 Mei 2013. http://journal.fkm.ui.ac.id/kesmas/article/view/4

Bahiyatun. (2009). Buku Ajar Asuhan Kebidanan Nifas Normal. Jakarta : EGC

Dinas Kesehatan Provinsi Aceh. (2016). Profil Kesehatan Aceh 2015. http://dinkes.acehprov.go.id

Kemenkes. (2016). Profil Kesehatan Indonesia Tahun 2015. Kementrian Kesehatan Republik Indonesia.

Nuryani. (2012). Hubungan Pola Makan, Sosial Ekonomi, Antenatal Care dan Karakteristik Ibu Hamil dengan Kasus Preeklampsia di Kota Makassar. Media Gizi Masyarakat. Vol. 2. No. 2 Agustus 2013.

Prawirohardjo, S. (2008). Ilmu Kebidanan. Jakarta : Yayasan Bina Pustaka Sarwono Prawirohardjo

Saifuddin, A B. (2009). Buku Acuan Nasional Pelayanan Kesehatan Maternal dan Neonatal. Jakarta : Yayasan Bina Pustaka Sarwono Prawirohardjo

Varney, H. (2008). Buku Ajar Asuhan Kebidanan. Edisi 4. Jakarta : EGC

Winkjosastro, H. (2007). Ilmu Kebidanan. Jakarta : Yayasan Bina Pustaka Sarwono Prawirohardjo

World Healht Organization (WHO). (2016). Angka Kematian Ibu. http://who.org. 
Journal of Healthcare Technology and Medicine Vol. 4 No. 2 Oktober 2018

Universitas Ubudiyah Indonesia

e-ISSN : 2615-109X 